\title{
Pengaruh umpan buatan terhadap hasil tangkapan pancing layang-layang di Selat Bangka
}

\author{
The effect of artificial bait on the catch of kite fishing in Bangka Strait \\ LA SUDIONO*, EMIL REPPIE dan ALFRET LUASUNAUNG \\ Program Studi Pemanfaatan Sumberdaya Perikanan, Fakultas Perikanan dan Ilmu Kelautan, \\ Universitas Sam Ratulangi, Manado 95115
}

\begin{abstract}
One of the economically important fisheries resources in Bangka Strait of North Sulawesi is needlefish (Tylosurus sp) known locally as sako. Common fishing gears used to catch needlefish is surface gill nets, drift gill nets and trolling; but kite fishing is more popular in the Strait of Bangka. The success of kite fishing is highly dependent on the availability of natural bait of small in size. The natural bait only caught by lift net during dark moon phases. Therefore it is necessary to do an experiment using artificial baits; so this study aimed to determine the effect of artificial bait on the catch of kite fishing. This research was done in Bangka Strait based on experimental method. There were two kinds of bait used, i.e. a natural bait of rainbow sardine (Dussumieria acuta), and an artificial bait of rubber fish. Catch data were from four units of kite fishing and analyzed using a $t$ test. The total catch during the study were 40 needlefish of Tylosurus crocodiles: 22 caught with natural bait and 18 caught with artificial baits. The analysis showed that the use of natural bait was not significantly different from the artificial bait on kite fishing to catch needlefish in Bangka Strait. Needlefish could be caught at wind speeds of 4-7 knots.
\end{abstract}

Keywords: kite fishing, artificial bait, wind speeds, Bangka Strait

\begin{abstract}
ABSTRAK
Salah satu sumberdaya perikanan ekonomis penting yang dihasilkan dari perairan Selat Bangka Sulawesi Utara adalah ikan cendro (Tylosurus sp) yang dikenal dengan nama lokal sebagai ikan sako. Alat tangkap yang umum digunakan untuk menangkap ikan cendro ialah jaring insang permukaan, jaring insang hanyut dan pancing tonda; tetapi pancing layang-layang lebih populer di Selat Bangka. Keberhasilan penangkapan ikan dengan pancing layanglayang, sangat bergantung pada ketersediaan umpan alami berukuran kecil. Umpan alami tersebut hanya tertangkap dengan bagan pada sekitar bulan gelap. Oleh karena itu perlu dicobakan penggunaan umpan buatan; sehingga penelitian ini ditujukan untuk untuk mengetahui pengaruh umpan buatan terhadap hasil tangkapan pancing layanglayang. Penelitian ini dilakukan di Selat Bangka didasarkan pada metode eksperimental. Dua jenis umpan yang digunakan, yaitu umpan alami ikan japuh (Dussumieria acuta) dan umpan buatan berupa ikan karet. Data tangkapan dikumpulkan menggunakan empat unit pancing layang-layang; dan data dianalisis dengan uji $t$. Hasil tangkapan selama penelitian berjumlah 40 ekor ikan cendro dan hanya jenis Tylosurus crocodilus; sebanyak 22 ekor tertangkap dengan umpan alami dan 18 ekor tertangkap dengan umpan buatan. Hasil analisis menunjukkan bahwa penggunaan umpan alami tidak berbeda nyata dengan umpan buatan pada pancing layang-layang untuk menangkap ikan cendro di perairan Selat Bangka. Ikan cendro dapat tertangkap pada kecepatan angin antara 4-7 knot.
\end{abstract}

Kata-kata kunci: pancing layang-layang, umpan buatan, kecepatan angin, Selat Bangka

\section{PENDAHULUAN}

Salah satu sumberdaya perikanan ekonomis penting yang dihasilkan dari perairan Sulawesi Utara adalah ikan cendro (Tylosurus sp), dan dikenal dengan nama lokal sebagai ikan sako. Ikan ini me-

\footnotetext{
*Penulis untuk penyuratan; email: Sudiono_la@yahoo.com
}

rupakan ikan pelagis yang hidup dekat permukaan dan sulit ditangkap dalam jumlah banyak karena pergerakannya sangat gesit (Yusuf,2010).

Menurut FAO (1995), karakteristik pemanfaatan sumberdaya hayati laut yang ramah lingkungan, meliputi: selektivitas tinggi, hasil tangkapan sampingan rendah, tidak merusak lingkungan, 
tidak menangkap spesies yang dilindungi, pengoperasian alat tidak membahayakan nelayan, dan tidak beroperasi di daerah terlarang.

Hasil wawancara dengan nelayan di Selat Bangka menyebutkan bahwa jaring insang dapat menangkap ikan cendro lebih banyak, tetapi tingkat kerusakan jaring cukup tinggi karena tersangkut karang, dan untuk memperbaikinya membutuhkan waktu selama tiga hari; sehingga alternatif pilihan yang memadai adalah menggunakan pancing layang-layang (kite fishing).

Pancing layang-layang sering digunakan oleh nelayan untuk menangkap ikan cendro di perairan Selat Bangka Kabupaten Minahasa Utara, karena kontruksinya sederhana, relatif murah dan mudah dioperasikan dengan perahu ukuran kecil. Kite fishing adalah memancing dari perahu dengan menggunakan layang-layang untuk menjauhkan umpan pada jarak tertentu dari perahu; juga untuk menjaga umpan agar tetap berada di permukaan air, karena teknik ini biasanya dilakukan untuk menangkap ikan-ikan permukaan (Ellis, 2012). Pancing layang-layang diklasifikasikan dalam pancing ulur yaitu pancing yang dioperasikan dengan bantuan layang-layang. Berdasarkan klasifikasi standar internasional terhadap alat tangkap ikan dan beberapa contoh alat tangkap ikan dengan kode LX.09.9.0 (Anonimous,2005).

Pancing layang-layang merupakan alat tangkap ikan cendro tradisional, yang hanya menggunakan bahan dan alat sederhana, tetapi mudah dioperasikan dengan hanya menggunakan perahu ukuran kecil, dan dapat diintroduksi sebagai obyek wisata bahari yang menarik. Keberhasilan penangkapan ikan dengan pancing layang-layang, sangat bergantung pada ketersediaan umpan alami yang berukuran kecil. Umpan alami tersebut tertangkap dengan bagan (lift net) pada sekitar bulan gelap. Hal ini berarti bahwa pancing layang-layang tidak dapat dioperasikan sepanjang waktu tiap bulan. Oleh karena itu, dalam penelitian ini akan dicobakan penggunaan umpan buatan (artificial bait) untuk mengetahui apakah berpengaruh terhadap hasil tangkapan ikan cendro.

Secara umum penelitian ini bertujuan untuk mengembangkan teknologi pemanfaatan sumberdaya perikanan ikan cendro yang ramah lingkungan dan berkelanjutan; dan secara khusus penelitian ini bertujuan untuk: (1) mempelajari pengaruh jenis umpan buatan terhadap hasil tangkapan ikan cendro dengan pancing layang-layang; dan (2) mengidentifikasi jenis-jenis ikan cendro yang tertangkap dengan pancing layang-layang.

\section{METODE PENELITIAN}

Penelitian ini dilakukan dengan mengikuti metode eksperimental yaitu suatu rancangan percobaan yang diujicobakan untuk memperoleh informasi tentang persoalan yang sedang diteliti. Melalui metode ini dapat diperoleh informasi yang diperlukan dalam melakukan penelitian tentang persoalan yang akan dibahas sehingga akan dihasilkan suatu kesimpulan sesuai dengan tujuan penelitian.

Teknik pengumpulan data untuk mendekati tujuan pertama yang telah ditetapkan, yaitu mempelajari pengaruh umpan buatan terhadap hasil tangkapan, dilakukan dengan mengoperasikan 4 unit alat tangkap pancing layang-layang. Dua jenis umpan yang digunakan, yaitu umpan alami ikan japuh (Dussumieria acuta) dan umpan buatan dari karet berbentuk ikan kecil.

\section{Teknik analisis data}

Untuk memenuhi persyaratan analisis dalam menarik kesimpulan, maka dirumuskan hipotesis sebagai berikut:

$\mathrm{H}_{0}$ : Hasil tangkapan pancing layang-layang yang menggunakan umpan buatan tidak berbeda nyata dengan yang menggunakan umpan alami; $\mathrm{H}_{1}$ : Hasil tangkapan pancing layang-layang yang menggunakan umpan buatan berbeda nyata dengan yang menggunakan umpan alami;

di mana $\mathrm{H}_{0}$ diterima $\left(\mathrm{H}_{1}\right.$ ditolak) apabila $\mathrm{t}_{\text {hitung }} \leq \mathrm{t}$ tabel, $\mathrm{H}_{0}$ ditolak $\left(\mathrm{H}_{1}\right.$ diterima $)$ apabila $\mathrm{t}$ hitung $>\mathrm{t}$ tabel. Selanjutnya $t$ dihitung dengan mengunakan analisis komparatif dua sampel berkorelasi (Soepeno, 2002), dengan rumusan sebagai berikut:

$$
T=\frac{\bar{X}-\bar{Y}}{\sqrt{\frac{\sum D^{2}-\frac{\left(\sum D\right)^{2}}{n}}{n(n-1)}}}
$$

Keterangan:

$\mathrm{T}=\mathrm{t}$ hitung

$\overline{\mathrm{X}}=\mathrm{X}$ rata - rata (umpan alami)

$\overline{\mathrm{Y}}=$ Y rata - rata (umpan buatan)

$\mathrm{D}=$ Beda skor pertama dan kuadrat beda skor

$\mathrm{n}=$ jumlah hasil

\section{Deskripsi alat tangkap}

\section{Penggulung dan tali ulur}

Penggulung tali terbuat dari bahan plastik berbentuk bulat dengan diameter $12 \mathrm{~cm}$, berfungsi sebagai tempat untuk menggulung tali pancing dan 
pegangan pada waktu pengoperasian alat seperti pada Gbr. 2.

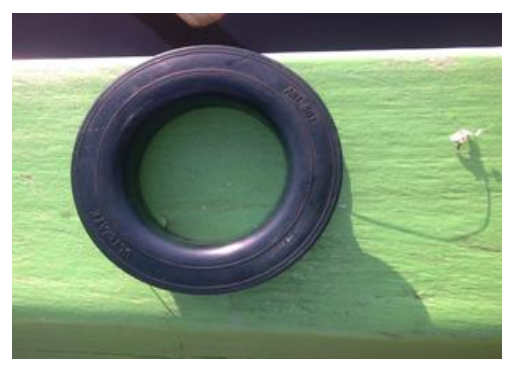

Gambar 2. Penggulung dan tali ulur

\section{Joran}

Joran atau tangkai pancing adalah bagian alat tangkap yang berfungsi sebagai media tempat dilaluinya tali ulur untuk menaikkan layanglayang; terbuat dari bambu (bulu tui) dengan panjang sekitar $4 \mathrm{~m}$; berdiameter $5 \mathrm{~cm}$ pada bagian pangkal dan $1 \mathrm{~cm}$ pada bagian ujung, yang dipasangi cincin sebagai tempat lewat tali utama seperti pada (Gbr. 3\&4).

\section{Layang-layang}

Layang-layang yang digunakan secara tradisional untuk menangkap ikan cendro di Selat Bangka adalah daun kiter (Polypodium quercifollum) seperti pada Gbr. 5. Daun dipilih yang berukuran lebar, kering dan tidak sobek. Sebagai ganti ekor, layang-layang diikatkan tali pancing yang mata kailnya diganti dengan jerat berumpan.

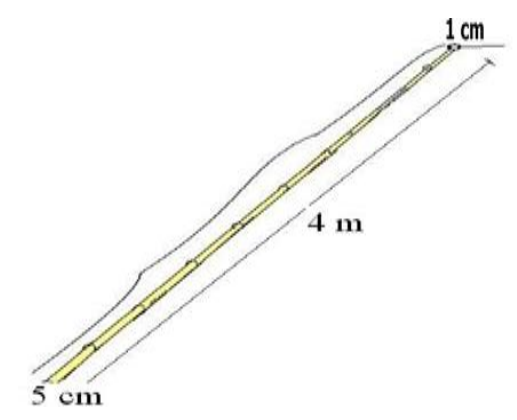

Gambar 3. Joran atau tangkai pancing

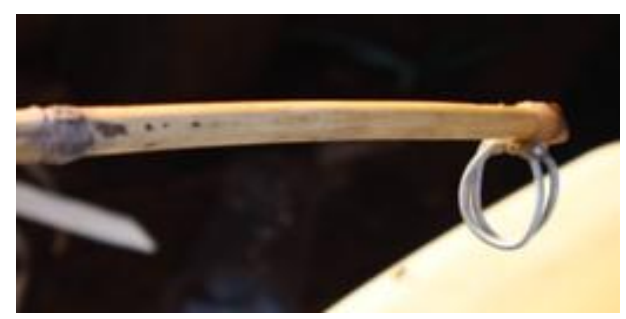

Gambar 4. Cincin (gelang) tali utama pada ujung joran

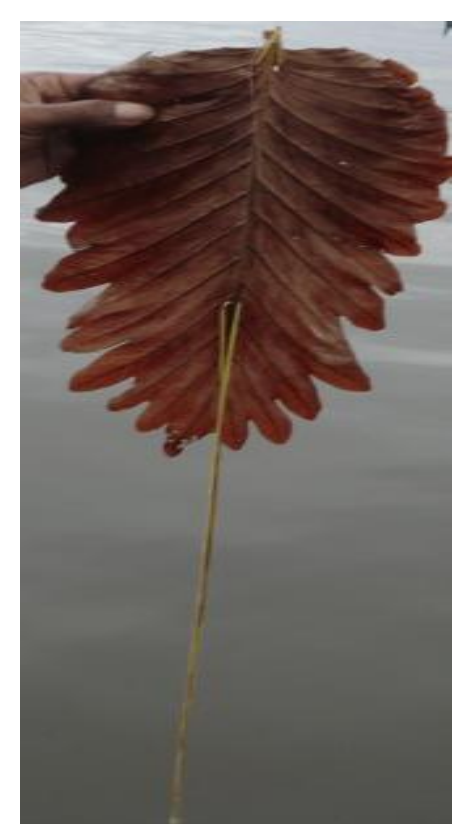

Gambar 5. Daun kiter (Polypodium quercifollum)

\section{Tali jerat}

Tali utama (tali ulur) terbuat dari nylon polyamide monofilament (PA mono) nomor 250, dengan panjang $200 \mathrm{~m}$. Tali jerat juga dari nylon polyamide monofilament (PA mono) nomor 250; dibentuk melingkar menggunakan simpul laso, yang dimasukkan ke dalam tubuh ikan umpan alami, sedangkan pada umpan buatan cara memasukan sama seperti umpan alami yang sudah dirancang sedemikian rupa agar dapat menyerupai umpan alami.

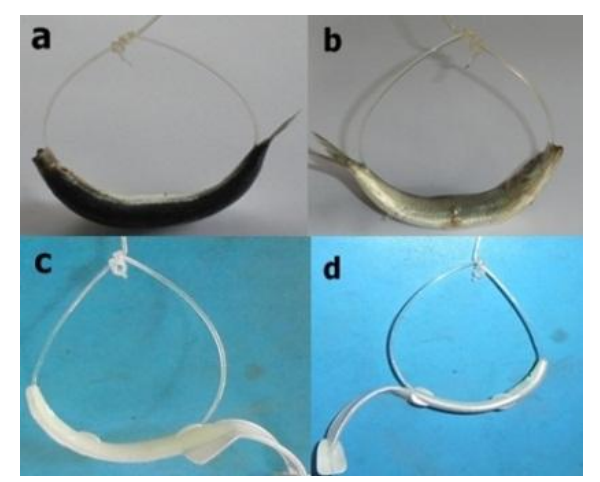

Gambar 6. Pemasangan tali jerat pada umpan

Gambar dan spesifikasi alat tangkap pancing layang-layang dapat dilihat pada Gbr. 7 dan Tabel 1 . 


\section{Spesifikasi perahu penangkapan}

Perahu penangkap yang digunakan adalah tipe pelang empat unit dengan mesin katinting 5,5 PK; dimensi utama perahu pertama: panjang $5,5 \mathrm{~m}$, lebar $0,43 \mathrm{~m}$, tinggi $0,65 \mathrm{~m}$; perahu kedua: panjang $5,30 \mathrm{~m}$, lebar $0,41 \mathrm{~m}$, tinggi $0,62 \mathrm{~m}$; perahu ketiga: panjang $5,8 \mathrm{~m}$, tinggi $0,30 \mathrm{~m}$, lebar $0,30 \mathrm{~m}$; perahu keempat: panjang $5,9 \mathrm{~m}$, tinggi $0,37 \mathrm{~m}$, dan lebar $0,42 \mathrm{~m}$.

\section{Kesiapan alat tangkap}

Kegiatan-kegiatan yang dilakukan sebelum berangkat ke daerah operasi adalah mempersiapkan segala sesuatu yang berhubungan dengan operasi penangkapan yaitu dimulai dari menyiapkan daun kiter yang akan digunakan sebagai layang-layang dalam pengoperasian alat tangkap ini. Daun yang dipilih biasanya yang berukuran lebar, kering, dan tidak sobek. Selain daun kiter, persiapan yang lain adalah menyiapkan umpan.

\section{Daerah penangkapan}

Daerah penangkapan pancing layang-layang dilakukan pada enam ruang, yaitu 1) napo putus dengan posisi geografis sekitar $1^{0} 42^{\prime} 28.72$ " $\mathrm{N}$ dan $125^{\circ} 1$ '50.43" E; 2) napo ila $1^{0} 42^{\prime} 50.97$ " $\mathrm{N}$ dan $125^{0} 2$ '1.32” E; 3) napo paser $1^{0} 42^{\prime} 31.19^{\prime \prime} \mathrm{N}$ dan $125^{0} 2$ '16.24" E; 4) napo panjang $1^{0} 41^{\prime} 36.29 " \mathrm{~N}$ dan $125^{\circ} 2^{\prime} 42.32^{\prime \prime}$ E; 5) napo manu $1^{0} 41^{\prime} 33.37^{\prime \prime} \mathrm{N}$ dan $125^{\circ} 2^{\prime} 42.32^{\prime \prime}$ E, serta napo daun $1^{\circ} 41^{\prime} 12.27^{\prime \prime}$ $\mathrm{N}$ dan $125^{\circ} 3^{\prime} 15.94^{\prime \prime}$ E. Sedangkan pengoperasian alat tangkap layang-layang dilakukan dari pagi jam 09.00 hingga sore hari jam 15.00.

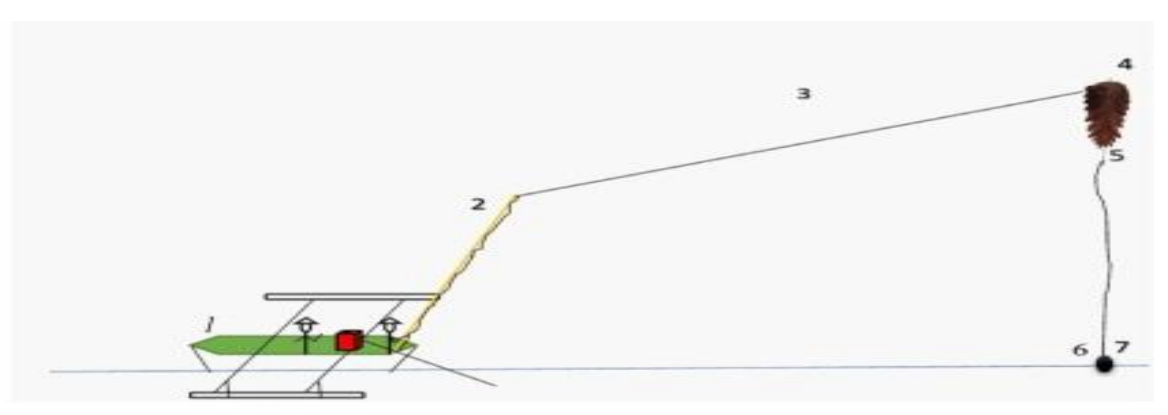

Gambar 7. Skema pancing layang-layang: 1) perahu pelang, 2) joran, 3) tali ulur, 4) layang-layang, 5) lidi daun kelapa, 6) jerat, dan 7) umpan

Tabel 1. Spesifikasi satu unit pancing layang-layang

\begin{tabular}{llllll}
\hline & Namabagian & Material & \multicolumn{1}{c}{$\begin{array}{c}\text { Lebar } \\
(\mathrm{m})\end{array}$} & $\begin{array}{c}\text { Panjang } \\
(\mathrm{m})\end{array}$ & Jumlah \\
\hline 1 & Penggulung & Plastik & $\Phi 0,12$ & - & 1 \\
2 & Tanggai/joran & Bambu & 0,5 & $4-5$ & 1 \\
3 & Taliulur & PA Mono & - & 200 & 1 \\
& & No.250 & & & \\
4 & Layang-layang & Daun/kiter & 0,16 & 0,22 & 1 \\
5 & Lidi daunkelapa & & - & 0,6 & 2 \\
6 & Tali jerat & PA Mono & $\Phi 0,27$ & 0,27 & 1 \\
& & No.250 & & & \\
\hline
\end{tabular}



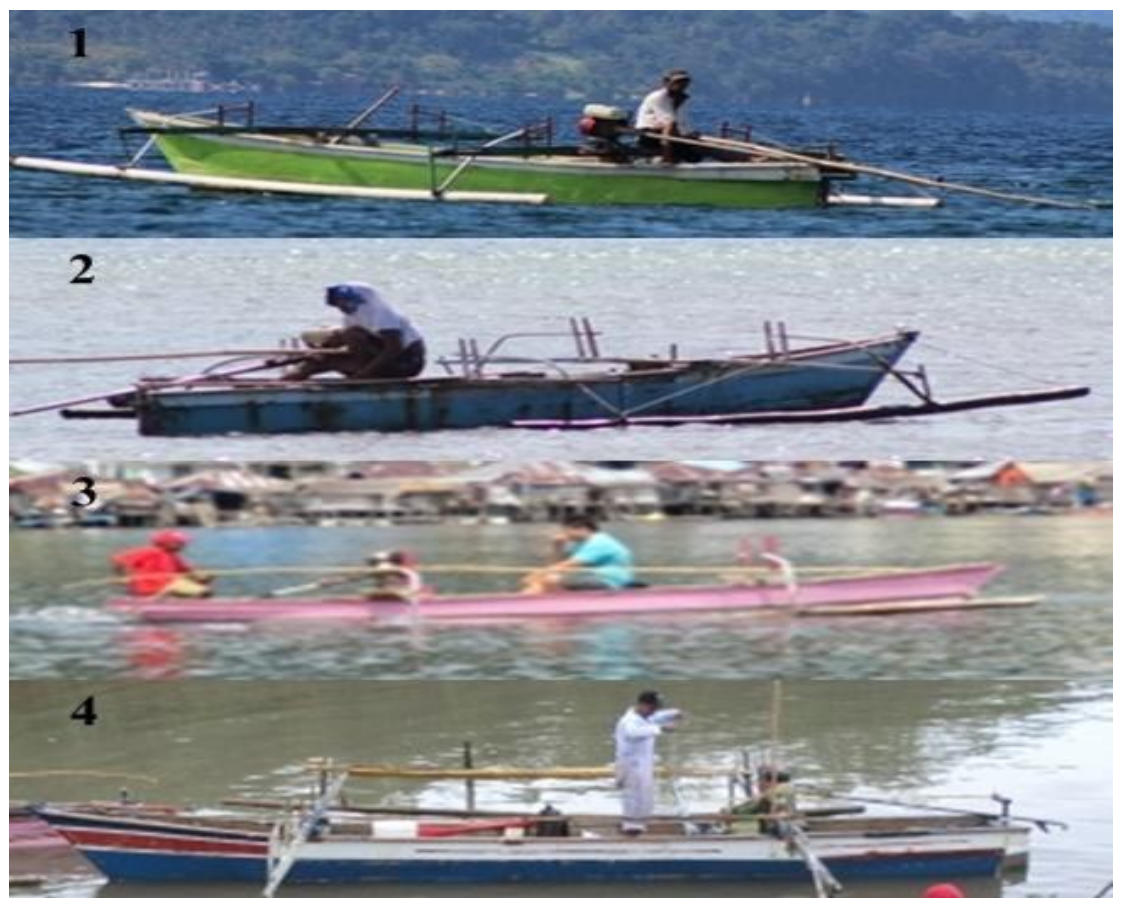

Gambar 8. Empat unit perahu tipe pelang yang digunakan

\section{Pengoperasian pancing layang-layang}

Tiupan angin merupakan faktor yang penting, layangan dengan jerat yang sudah berumpan, diterbangkan melalui bantuan tangkai joran dan angin, kemudian diulur perlahan-lahan sampai pada jarak yang diinginkan (15-30 m); tetapi tetap menjaga jerat berumpan di permukaan air dan tidak terangkat ke udara.

Ketika terasa umpan dimakan ikan cendro, maka joran disentak sehingga rahang bagian atas ikan terjerat; tali pancing ditarik ke perahu sampai ikan tertangkap. Ikan dilepaskan dengan memotong tali utama secara serong meruncing. Tali utama yang meruncing tersebut digunakan menusuk tubuh umpan untuk membentuk jerat baru; sehingga pemancingan berikutnya segera dapat dilanjutkan berulang kali. Hasil tangkapan dilaporkan setiap 1 jam sekali oleh si pemancing, dan selanjutnya dicatat jenisnya di atas perahu.

\section{HASIL DAN PENELITIAN}

\section{Hasil tangkapan}

Hasil tangkapan pancing layang-layang selama penelitian berjumlah 40 ekor ikan cendro dan hanya jenis Tylosurus crocodilus; sebanyak 22 ekor tertangkap dengan umpan alami dan 18 ekor tertangkap dengan umpan buatan.

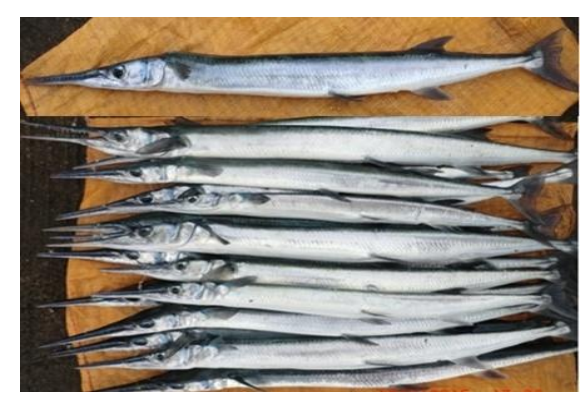

Gambar 9. Hasil tangkapan ikan cendro (Tylosurus crocodilus) 
Tabel 2. Jumlah hasil tangkapan (ekor) pancing layang-layang menurut perlakuan.

\begin{tabular}{llcccc}
\hline & Jam Operasi & \multicolumn{2}{c}{ Perlakuan Jenis Umpan } & Total & \multirow{2}{*}{ Rataan } \\
\cline { 3 - 4 } & Penangkapan & Alami & Buatan & & \\
\hline 1 & $09: 05-10: 00$ & 2 & 1 & 3 & 1,5 \\
2 & $10: 05-11: 00$ & 4 & 2 & 6 & 3,0 \\
3 & $11: 05-12: 00$ & 3 & 5 & 8 & 4,0 \\
4 & $12: 05-13: 00$ & 7 & 5 & 12 & 6,0 \\
5 & $13: 05-14: 00$ & 5 & 3 & 8 & 4,0 \\
6 & $14: 05-15: 00$ & 1 & 2 & 3 & 1,5 \\
\hline Total & & 22 & 18 & 40 & - \\
\hline Rataan & & 3,67 & 3,00 & 6,67 & - \\
\hline
\end{tabular}

Tabel 3. Analisis uji t terhadap hasil tangkapan pancing layang-layang

\begin{tabular}{|c|c|c|c|c|c|}
\hline & $\begin{array}{l}\text { Jam Operasi } \\
\text { Penangkapan }\end{array}$ & $\begin{array}{c}\text { Umpan } \\
\text { Alami (X) }\end{array}$ & $\begin{array}{c}\text { Umpan } \\
\text { Buatan (Y) }\end{array}$ & $\mathrm{D}(\mathrm{X}-\mathrm{Y})$ & $\mathrm{D}^{2}$ \\
\hline 1 & 09:05-10:00 & 2 & 1 & 1 & 1 \\
\hline 2 & $10: 05-11: 00$ & 4 & 2 & 2 & 4 \\
\hline 3 & 11:05-12:00 & 3 & 5 & -2 & 4 \\
\hline 4 & $12: 05-13: 00$ & 7 & 5 & 2 & 4 \\
\hline 5 & $13: 05-14: 00$ & 5 & 3 & 2 & 4 \\
\hline 6 & $14: 05-15: 00$ & 1 & 2 & -1 & 1 \\
\hline \multicolumn{2}{|c|}{ Total } & 22 & 18 & 4 & 18 \\
\hline \multicolumn{2}{|c|}{ Rataan } & 3.67 & 3,00 & & \\
\hline
\end{tabular}

Hasil analisis menunjukkan bahwa t hitung $=$ $0,38<\mathrm{t}$ tabel $\mathbf{0 , 0 5 ; 5}=2,571$; sehingga menerima $\mathrm{H}_{0}$ dan menolak $\mathrm{H}_{1}$, di mana hal ini ini menjelaskan bahwa penggunaan umpan alami tidak berbeda nyata dengan umpan buatan pada pancing layanglayang untuk menangkap ikan cendro di perairan Selat Bangka.

\section{Hasil pengukuran kecepatan angin}

Kecepatan angin diukur secara sederhana dengan menerbangkan kertas timah rokok yang diikat dengan tali monofilament nomor 6 sepanjang $5 \mathrm{~m}$. Jumlah waktu (detik) yang dibutuhkan untuk melintasi jarak $5 \mathrm{~m}$ dicatat dan diulang sebanyak 3 kali. Asumsi bahwa kertas timah dapat terbang sempurna dan berat tali diabaikan. Kondisi kecepatan angin di lokasi penelitian dikategorikan rendah dan menengah. Hasil pengukuran waktu tempuh kertas timah terbawa angin disajikan dalam Tabel 4; dan hasil perhitungannya disajikan dalam Tabel 5.
Tabel 4. Hasil pengukuran waktu tempuh kertas timah sepanjang $5 \mathrm{~m}$.

\begin{tabular}{lcc}
\hline \multirow{2}{*}{ Ulangan } & \multicolumn{2}{c}{ Waktu tempuh (det) } \\
\cline { 2 - 3 } & Rendah & Menengah \\
\hline 1 & 2 & 1 \\
2 & 3 & 2 \\
3 & 2 & 1 \\
\hline Total & 7 & 4 \\
\hline Rataan & 2,33 & 1,33 \\
\hline
\end{tabular}

\section{Pembahasan}

Kecepatan angin juga merupakan faktor yang sangat penting; karena jika angin terlalu lemah, layangan tidak dapat naik ke udara untuk mengangkat umpan; sebaliknya jika angin terlalu kuat, layangan terbang tinggi dan dapat berputarputar, sehingga ikan tidak tertangkap. Kecepatan angin pada saat penelitian diperkirakan 4-7 knot, 
Tabel 5. Hasil perhitungan kecepatan angin pada saat penelitian

\begin{tabular}{|c|c|c|c|c|c|}
\hline & \multirow{2}{*}{$\begin{array}{c}\text { Keadaan kecepatan } \\
\text { angin }\end{array}$} & \multirow{2}{*}{$\begin{array}{c}\text { Panjang lintasan } \\
(\mathrm{cm})\end{array}$} & \multirow{2}{*}{$\begin{array}{c}\text { Rata-rata waktu } \\
\text { tempuh (det) }\end{array}$} & \multicolumn{2}{|c|}{ Kecepatan angin } \\
\hline & & & & $\mathrm{cm} /$ detik & knot \\
\hline 1 & Rendah & 500 & 2,33 & 214,29 & 4,17 \\
\hline 2 & Menengah & 500 & 1,33 & 375,00 & 7,29 \\
\hline
\end{tabular}

di mana pada kondisi ini ikan cendro dapat tertangkap dan hal ini terjadi antara jam 11:00 14:00.

Berdasarkan jumlah hasil tangkapan pancing layang-layang, maka umpan alami relatif lebih banyak (22 ekor) dibandingkan dengan umpan buatan (18 ekor), tetapi secara statistik tidak berbeda nyata. Diakui bahwa pemasangan tali laso pada umpan buatan relatif lebih lama dari pada umpan buatan, dan konstruksinya masih perlu penyempurnaan lebih lanjut.

\section{KESIMPULAN}

1. Penggunaan umpan alami dan umpan buatan tidak berbeda terhadap hasil tangkapan ikan cendro dengan pancing layang-layang.
2. Ikan cendro hasil tangkapan pancing layanglayang hanya terdiri dari satu jenis, yaitu Tylosurus crocodilus.

\section{DAFTAR PUSTAKA}

Anonimous. 2005. Istilah defenisi alat tangkap pancing standar nasional Indonesia. Materi perubahan rancangan. Ditjen Perikanan Tangkap.BPPI, Semarang.

Ellis, 2012. Kite Fishing Tips, Rigging Techniques, and Essential Gear.

FAO. 1995. Karakteristik Pemanfaatan Sumberdaya Hayati Laut yang Ramah Lingkungan.

Soepeno, B. 2002. Statistik Terapan. Penerbit Rineka Cipta.

Yusuf. 2010. Wisata Bahari Kota Makasar. http://bahasa.Makasar.go.id/, diakses tanggal 23 Februari 2014. 